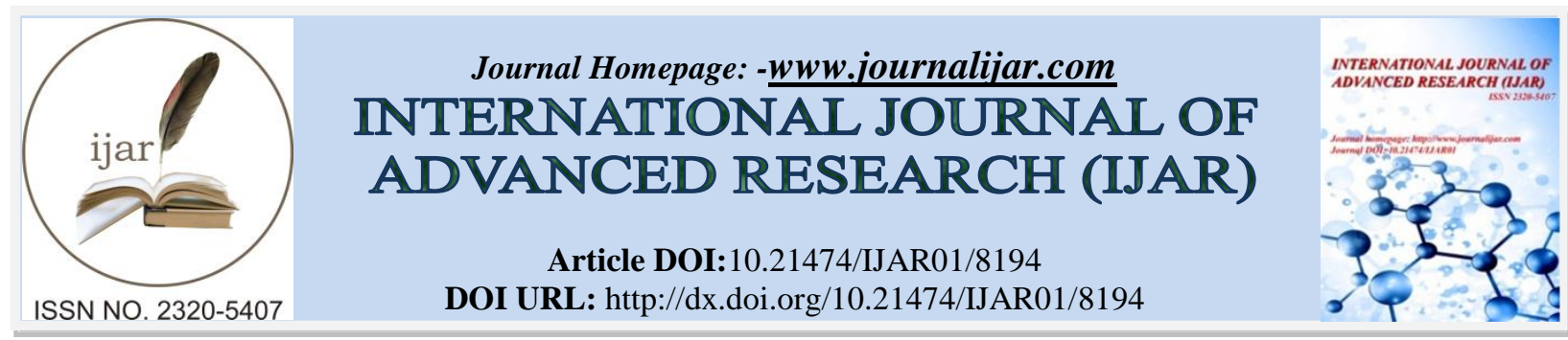

RESEARCH ARTICLE

\title{
DETECTION OF HUMAN PAPILLOMMA VIRUS AND EPSTEIN-BARR VIRUS IN SUBJECTS OF ORAL LEUKOPLAKIA BY POLYMERASE CHAIN REACTION(PCR)- A PRELIMINARY STUDY
}

Asha R Iyengar, Seema Patil, Subash BV, Revan Joshi, Meghna Gohain, Vani MH And Megha DB. Department of Oral Medicine and Radiology, DA Pandu Memorial RV Dental College, Bangalore, Karnataka, India.

\section{Manuscript Info}

Manuscript History

Received: 12 October 2018

Final Accepted: 14 November 2018

Published: December 2018

Keywords:-

Oral leukoplakia, HPV, EBV, PCR, Dysplasia.

\section{Abstract}

Viruses such as HPV and EBV have been implicated in the etiopathogenesis of oral precancer and cancer, however the association is inconclusive. Hence, the present study aimed to determine the incidence of HPV and EBV in subjects with oral leukoplakia. The association of HPV and EBV with age, clinical form of leukoplakia and dysplasia was also evaluated.

Methodology:-A total of 50 subjects with leukoplakia(clinically and histopathologically confirmed) and 50 age and gender matched individuals were included in the study. Tissue specimens from all the subjects were subjected to PCR analysis for detection of HPV and EBV.

Results:-The expression of HPV and EBV was higher in the leukoplakia group as compared to controls and this difference was statistically significant with respect to $\mathrm{HPV}$ (p value :0.03), but not with respect to EBV ( $\mathrm{p}$ value :0.12). There was no significant association between HPV and EBV with respect to clinical forms of leukoplakia and dysplasia. The expression of EBV was significantly higher in subjects over 56 years as compared to the other age groups ( $\mathrm{p}$ value : 0 $.03)$.

Conclusion:-Although, a significant difference in the incidence of HPV was noted between subjects with OL and controls, further evaluation of the expression of E6 and E7 oncoproteins would provide confirmatory evidence on the role of HPV in leukoplakia. It may be inferred that EBV has limited role in the etiology of leukoplakia.

Further studies would give better clarity on the role of EBV in leukoplakia.

\section{Introduction:-}

Oral leukoplakia is one of the most common oral potentially malignant disorders. Around 70-90\% of leukoplakias are associated with tobacco in the smoked/ smokeless form ${ }^{1}$.A subset of leukoplakias are not associated with any known etiologic factor. However, viruses (HPV, EBV, HHV6 and herpes simplex) have been investigated for their possible role in the etio-pathogenesis of leukoplakias.

Corresponding Author:-Asha R Iyengar. 
The human papilloma virus (HPV) is an epitheliotropic DNA virus that contributes to $70 \%$ of cervical cancers worldwide. A strong casual association has been reported between HPV and carcinomas of base of the tongue and pharynx/tonsillar regions in contrast to weak casual association between HPV and oral squamous cell carcinoma ${ }^{1,2}$. A recent meta-analysis determined that the likelihood of HPV being detected in pre- cancerous lesions is 2-3 times greater and in oral squamous cell carcinoma, it is 4-5 times greater than in normal oral mucosa. This suggests that there may be some link between HPV and oral pre- cancerous and cancerous lesions. ${ }^{3}$

The Epstein Barr virus (EBV) is a gamma- herpesvirus with a DNA genome, which infects more than $90 \%$ of world population. This virus is involved in several malignancies including Burkitt's lymphoma, Hodgkin's lymphoma and nasopharyngeal carcinoma. Limited number of studies have evaluated the association of EBV with OSCC. A wide range in the prevalence of $\mathrm{EBV}$ in OSCC has been observed ranging from $22 \%$ in Yemen to $80 \%$ in UK. A higher prevalence of EBV has been observed in Industrialised countries compared to developing countries ${ }^{4}$. The results of a current meta-analysis suggest that EBV infection is significantly associated with increased risk of OSCC. However, additional high-quality studies with larger sample sizes are needed to further confirm the relationship between EBV and OSCC $^{5}$. Similarly, very few studies have evaluated the association between EBV and leukoplakia with contradictory results.

Over the years, Polymerase Chain Reaction (PCR) has emerged as a sensitive method for precise detection of HPV and EBV having a high specificity and sensitivity. PCR can detect 1-10 viral copies per reaction as compared to in situ hybridization which detects 25 copies per reaction.

With the above background, the present study aimed to determine the incidence of HPV and EBV in subjects with oral leukoplakia by PCR analysis of tissue samples. The association of HPV and EBVin the leukoplakia group withage, clinical forms, and degree of dysplasia was also evaluated.

\section{MATERIALS AND METHOD:}

The subjects reporting to the Department of Oral Medicine and Radiology with various dental complaints were screened for the presence of leukoplakia.

A total of 50 subjects satisfying the clinical criteria of leukoplakia (suggested by Warnakulasuriya et al, in 2007) were included in the study after obtaining a written consent. 50 age and gender matched individuals requiring dental extraction were included as controls. Subjects with squamous papilloma, verruca vulgaris, condyloma acuminatum were excluded from the study. A thorough history with regard to tobacco habits was obtained.

This was followed by clinical examination with respect to the location and clinical forms of leukoplakia. After obtaining the routine hematologic report, an incisional biopsy was performed for subjects with leukoplakia, under local anaesthesia. The specimen obtained was divided into two parts.

One section was transported in $10 \%$ formalin solution for histopathologic evaluation and determination of degree of dysplasia.The other section was stored at minus 20 degree of temperature and was transported within a week for further PCR investigation for detection of HPV and EBV.

In controls, during the extraction procedure, a small bit of the gingival tissue was excised and stored in a similar manner as described above and sent for PCR evaluation for detection of HPV and EBV.

\section{Results:-}

In the present study as elaborated in Table 1, the age range of subjects with leukoplakia was 24-77 years with a mean age of 47.1 years. Mostof the subjects with leukoplakia were males (92\%) and 8\% were females.

The most common adverse habit prevalentamongst subjects with leukoplakia was smoking which was observed in 78 $\%$ of the subjects. One subject did not have any associated etiological factor (idiopathic) (Table 2). The mean duration of smoking habit amongst leukoplakic group was 18.73 years. while the daily frequency of smoking habit was 10 times/day.

The most common clinical form of leukoplakia was the homogenous form, noted in 38 subjects (76\%). Nonhomogenous form was observed in 12 subjects (24\%). The buccal mucosa was the most common site of involvementfor both homogenous (78.9\%) and non- homogenous forms $(50 \%)$. 
The overall expression of HPV was higher in the leukoplakia group $(n=29 ; 58 \%)$ ascompared to controls $(n=18 ; 36 \%)$ and this difference was statistically significant(chi- square test;p value : 0.03 ). (Table 3 )

Further, the difference in the incidence of HPV 16 and HPV 18 was individualy evaluated between the subjects of leukoplakia and control. There was no significant difference in the incidence of HPV 16 and 18 between the subjects of leukoplakia and control (chi- square test;p value: 0.06 and p value: 0.54 respectively). Of the 29 HPV positive subjects, $22(75 \%)$ were positive for HPV 16 and 7 (25\%)were positive for HPV 18.

The expression of EBV was also higher in the leukoplakia group(n=12;24\%) in comparison to the control group $(\mathrm{n}=6 ; 12 \%)$, but this difference was not statistically significant(chi- square test;p value :0.12) (Table 3)

The expression of HPV did not vary amongst subjects with leukoplakia of different age groups(chi- square test; $\mathrm{p}$ value - 0.05). However, the expression of EBV was higher in subjects over 56 years $(n=10 ; 62.5 \%)$ as compared to the other age groups and this difference was statistically significant (chi square test; $\mathrm{p}$ value : 0.03 ). (Table4)

The association of HPV with different clinical forms of leukoplakia showed no statistical significant difference between the homogenous and non- homogenous forms (p value:0.19). Similarly, association of EBV with any clinical form of leukoplakia was not evident(chi square test; $p$ value :0.79) (Table5).

There was no statistical significant association of both HPV ( $p$ value:0.06) and EBV (p value :0.05) with dysplasia in leukoplakia lesions(Table 6)

Table 1:-Age and Gender Distribution in Leukoplakia and Control Group

\begin{tabular}{|c|c|c|c|c|c|}
\hline \multirow{2}{*}{ Variables } & \multirow[b]{2}{*}{ Category } & \multicolumn{2}{|c|}{ Leukoplakia } & \multicolumn{2}{|c|}{ Controls } \\
\hline & & $\mathrm{n}$ & $\%$ & $\mathrm{n}$ & $\%$ \\
\hline \multirow[t]{4}{*}{ Age } & $<25 \mathrm{Yrs}$ & 2 & $4 \%$ & 9 & $18 \%$ \\
\hline & $26-40$ yrs & 15 & $30 \%$ & 12 & $24 \%$ \\
\hline & $41-55$ yrs & 17 & $34 \%$ & 10 & $20 \%$ \\
\hline & $>56 \mathrm{yrs}$ & 16 & $32 \%$ & 19 & $38 \%$ \\
\hline \multirow[t]{2}{*}{ GENDER } & Males & 46 & $92 \%$ & 50 & $70 \%$ \\
\hline & Females & 4 & $8 \%$ & 15 & $30 \%$ \\
\hline
\end{tabular}


Table 2:-Distribution of adverse habits among Leukoplakia Group

Table2: Distribution of adverse habits among Leukoplakia Group

\begin{tabular}{|l|l|l|}
\hline Habits & $\mathrm{n}$ & $\%$ \\
\hline Smoking & 39 & $78 \%$ \\
\hline Quid & 4 & $8 \%$ \\
\hline Pan Masala & 1 & $2 \%$ \\
\hline Smoking \& Quid & 3 & $6 \%$ \\
\hline Smoking + Pan & 2 & $4 \%$ \\
\hline Idiopathic & 1 & $2 \%$ \\
\hline
\end{tabular}

Table 3:-Incidence of HPV \& EBV among Leukoplakia and Control groups using Chi square Test

Table3: Incidence of HPV \& EBV among Leukoplakia and Control groups using Chi square Test

\begin{tabular}{|c|c|c|c|c|c|c|c|}
\hline \multirow{2}{*}{$\begin{array}{l}\text { Types of } \\
\text { Viruses }\end{array}$} & \multirow[b]{2}{*}{ Category } & \multicolumn{2}{|c|}{$\begin{array}{l}\text { Leukoplakia } \\
{[\mathrm{N}=50]}\end{array}$} & \multicolumn{2}{|c|}{$\begin{array}{l}\text { Controls } \\
{[\mathrm{N}=50]}\end{array}$} & \multirow[b]{2}{*}{$\chi^{2}$} & \multirow[b]{2}{*}{ p-value } \\
\hline & & $\mathrm{n}$ & $\%$ & $\mathrm{n}$ & $\%$ & & \\
\hline \multirow[t]{2}{*}{ HPV } & Absent & 21 & $56 \%$ & 32 & $64 \%$ & \multirow[b]{2}{*}{4.86} & \multirow[b]{2}{*}{.03} \\
\hline & Present & 29 & $58 \%$ & 18 & $36 \%$ & & \\
\hline \multirow[t]{2}{*}{ EBV } & Absent & 38 & $76 \%$ & 44 & $88 \%$ & \multirow[b]{2}{*}{2.44} & \multirow[b]{2}{*}{.12} \\
\hline & Present & 12 & $24 \%$ & 6 & $12 \%$ & & \\
\hline
\end{tabular}


Table4: Association of HPV \& EBV with age in Leukoplakia group using Chi square Test

\begin{tabular}{|c|c|c|c|c|c|c|c|c|c|c|c|}
\hline \multirow{2}{*}{$\begin{array}{l}\text { Types } \\
\text { Viruses }\end{array}$} & \multirow[b]{2}{*}{ Category } & \multicolumn{2}{|c|}{$\leq 25 \operatorname{Yrs}[\mathrm{n}=2]$} & \multicolumn{2}{|c|}{$26-40$ yrs $[n=15]$} & \multicolumn{2}{|c|}{$41-55$ yrs $[\mathrm{n}=17]$} & \multicolumn{2}{|c|}{$>56$ yrs $[n=16]$} & \multirow[t]{2}{*}{$\begin{array}{l}\square^{2} \\
\text { Value }\end{array}$} & \multirow[t]{2}{*}{$\begin{array}{l}\text { P- } \\
\text { Value }\end{array}$} \\
\hline & & $\mathrm{n}$ & $\%$ & $\mathrm{n}$ & $\%$ & $\mathrm{n}$ & $\%$ & $\mathrm{n}$ & $\%$ & & \\
\hline \multirow[t]{2}{*}{ HPV } & Absent & 1 & $50 \%$ & 6 & $40 \%$ & 9 & $52.5 \%$ & 6 & $37.5 \%$ & \multirow{2}{*}{5.89} & \multirow{2}{*}{.05} \\
\hline & Present & 1 & $50 \%$ & 9 & $60 \%$ & 8 & $47.5 \%$ & 10 & $62.5 \%$ & & \\
\hline \multirow[t]{2}{*}{ EBV } & Absent & 1 & $50 \%$ & 0 & $0.00 \%$ & 13 & $75.5 \%$ & 10 & $23.5 \%$ & \multirow{2}{*}{4.58} & \multirow{2}{*}{.03} \\
\hline & Present & 1 & $50 \%$ & 0 & $0.00 \%$ & 4 & $23.5 \%$ & 6 & $37.5 \%$ & & \\
\hline
\end{tabular}

Table 5: Association of HPV \& EBV with clinical forms of Leukoplakia using Chi square Test

\begin{tabular}{|c|c|c|c|c|c|c|c|}
\hline \multirow{2}{*}{$\begin{array}{l}\text { Types of } \\
\text { Viruses }\end{array}$} & \multirow[b]{2}{*}{ Category } & \multicolumn{2}{|c|}{$\begin{array}{l}\text { Homogenous } \\
{[n=38]}\end{array}$} & \multicolumn{2}{|c|}{$\begin{array}{l}\text { Non- } \\
\text { Homogenous } \\
{[n=12]}\end{array}$} & \multirow{2}{*}{$\chi^{2}$} & \multirow[b]{2}{*}{ p-value } \\
\hline & & $\mathrm{n}$ & $\%$ & $\mathrm{n}$ & $\%$ & & \\
\hline \multirow[t]{2}{*}{ HPV } & Absent & 16 & $42 \%$ & 4 & $33 \%$ & \multirow[b]{2}{*}{1.73} & \multirow[b]{2}{*}{.19} \\
\hline & Present & 22 & $58 \%$ & 8 & $67 \%$ & & \\
\hline \multirow[t]{2}{*}{ EBV } & Absent & 29 & $76.3 \%$ & 9 & $75.0 \%$ & \multirow[b]{2}{*}{.07} & \multirow[b]{2}{*}{.79} \\
\hline & Present & 9 & $23.7 \%$ & 3 & $25.0 \%$ & & \\
\hline
\end{tabular}

Table6: Association of HPV \& EBV with degress of dysplasia in Leukoplakia group using Chi square Test

\begin{tabular}{|c|c|c|c|c|c|c|c|}
\hline \multirow{2}{*}{$\begin{array}{l}\text { Types of } \\
\text { Viruses }\end{array}$} & \multirow[b]{2}{*}{ Category } & \multicolumn{2}{|c|}{ No dysplasia (35) } & \multicolumn{2}{|c|}{ Dysplasia (15) } & \multirow[b]{2}{*}{$\chi^{2}$} & \multirow[b]{2}{*}{ p-value } \\
\hline & & $\mathrm{n}$ & $\%$ & $\mathrm{n}$ & $\%$ & & \\
\hline \multirow[t]{2}{*}{ HPV } & Absent & 16 & $46 \%$ & 5 & $33 \%$ & \multirow[b]{2}{*}{3.54} & \multirow[b]{2}{*}{.06 } \\
\hline & Present & 19 & $54 \%$ & 10 & $67 \%$ & & \\
\hline
\end{tabular}




\begin{tabular}{|l|l|l|l|l|l|l|l|} 
EBV & Absent & 26 & $75 \%$ & 13 & $85 \%$ & \\
& Present & 9 & $25 \%$ & 2 & $15 \%$ & 3.71 & .05 \\
\hline
\end{tabular}

\section{Discussion:-}

There has been conflicting evidence in literature with regard to the role of Human papillomaviruses (HPV) and Epstein- Barr Viruses (EBV) with oral potentially malignant disorderssuch as leukoplakia and their role in malignant transformation. In the present study, the incidence of HPV and EBV in subjects with leukoplakia was assessed. Further, association of HPVand EBV with age, habits, clinical form and dysplastic changes was evaluated

In the present study, the mean age of subjects with leukoplakia was 47.1 years in accordance with a Chinese ${ }^{6}$ and an Indian study ${ }^{7}$ in which the mean ages were 48 and 47 years respectively.

In older literature,leukoplakia was reported to be more prevalent in the elderly $\left(6^{\text {th }}\right.$ decade $)$ and was predominantly noted in males ${ }^{8,9}$. However, currently no difference in the prevalence of the lesion above and below 50 years has been demonstrated. In fact, an equal gender predilection has been noted in a few countries $\left(\mathrm{China}^{10}\right.$, Spain and Taiwan ${ }^{11}$ ) and on the contrary, a higher female preponderance has been reported in Germany ${ }^{12}$ and Italy ${ }^{14}$. Such variation can be ascribed to changing trends in lifestyles and stress among younger generation. Further, easy accessibility of tobacco products due to effective marketing strategies could also contribute to the changing trend.In India, 95-98\% of leukoplakia lesions have been reported in males (Gujarat and Bihar) which is in concurrence with the present study $(90 \%)^{14}$. The marked increase in the male to female ratio $(9: 1)$ in the present study can be attributed to the small sample size of the study. A reversal of the above trend has been observed in Kerala and Andhra Pradesh, where $80 \%$ of the lesions were found in females due to their habit of reverse smoking.$^{14}$

In the present study, $78 \%$ of the subjects with leukoplakia were smokers in agreement with previous reports from Brazi $1^{15}$, Hungary ${ }^{16}$, Japan ${ }^{17}$, Norway ${ }^{18}$ and Netherlands ${ }^{17}$. In contradiction to the above findings, smokeless tobacco was found to be a major contributory factor for leukoplakia in South East Asia and Sweden. ${ }^{19}$

One subject in the present study presented with no habits. Idiopathic leukoplakia has been reported in several studies and the prevalence ranges from ${ }^{13} 4.2 \%$ to $27 \%{ }^{20}$. A Brazilian study ${ }^{17}$ conducted in 2011 reported a higher malignant transformation rate of idiopathic leukoplakia.

The type of tobacco usage influences the distribution of the lesions. Buccal mucosa is the most common site of presentation of lesion in cigarette and bidi smokers. In the present study,72\% subjects presented with lesions on the buccal mucosa as most of the subjects were bidi/ cigarette smokers.Most (76\%) of the leukoplakia subjects presented with a homogenous variety of the disease whereas $24 \%$ of subjects presented with non- homogenous leukoplakia.Various studies conducted in Saudi Arabia, Netherlands, Norway,USA, Hungary and Brazil have reported a higher incidence of homogenous variety as compared to the non-homogenous type.

The frequency of epithelial dysplasia in leukoplakia varies between $<1 \%$ and $>30 \%$ across literature.

The reported prevalence of HPV infections in oral precancerous lesions shows an extreme variance from $0 \%$ to $100 \%$.A wide range in the prevalence of HPV in OL lesions has been observed in studies conducted across the world.

No association between HPV and OL was observed in an Iranian study ${ }^{22}$, whereas the prevalence was found to be as high as $45.7 \%$ in a Spanish study ${ }^{23}$.

In India, a study done by Bhosle et $\mathrm{al}^{24}$ reported no association of HPV with oral leukoplakia while Sikka et al and Mathew et al ${ }^{25}$ demonstrated the prevalence HPV to be $45 \%$ and $55 \%$ respectively by PCR analysis. Khanna et al ${ }^{26}$ demonstrated a prevalence of $40 \%$ by in- Situ hybridization (ISH) and Prakash $\mathrm{P}^{27}$ reported the prevalence of HPV to be $57.14 \%$ in subjects with oral leukoplakia on immunohistochemical analysis.In the present study, HPV DNA was detected in $58 \%$ of subjects with leukoplakia in accordance with the above mentioned Indian studies. A statistical 
significant difference in the incidence of HPV was observed between subjects with leukoplakia and controls. In the present study, incidence of HPV 16 was higher than HPV 18 in similarity with findings of Sikka et al.

Limited information is available in literature regarding the association of EBV and oral leukoplakia. A study done in a Hungarian population ${ }^{28}$ reported an incidence of $29.5 \%$ in subjects with OL by PCR analysis. In India, D'costa et al ${ }^{29}$ reported the incidence of EBV to be $15 \%$.

The wide variation in HPV prevalence may be caused by differences in HPV detection methods. HPV DNA detection methods include immunoperoxidase, immunofluorescence, in situ hybridization, southern blot, dot blot, reverse blot hybridization and polymerase chain reaction (PCR). Amongst these methods, PCR has highest sensitivity and can detect even a single copy of viral DNA per infected cell. Differences in ethnical or geographical origins of the subjects examined may also contribute to the variation. Also, clustering of lesions from various anatomical regions of the upper aerodigestive tract and not just the oral cavity may lead to varied results ${ }^{30}$.

In the present study, EBV DNA was detected in $28 \%$ of subjects with oral leukoplakia in concurrence with Hungarian study. There was no statistical significant difference in the incidence of EBV between subjects with leukoplakia and controls.

In the present study, there was no association between clinical variants of OL and HPV infection. This finding was in accordance with an Italian study which reported no association between any specific clinical variant of OL and HPV. Further, no association was noted between age and degree of dysplasia with HPV infection in the present study. Similar findings were noted in a Taiwanese study. ${ }^{4}$

Similarly, no association was noted between clinical variants of OL and degree of dysplasia with EBV infection. However, a significant association was noted between EBV and subjects above 56 years. Since there is very limited information regarding association of EBV infection in OL in literature, the results of the present study could not be compared with other studies.

The association of tobacco and HPV infection is still controversial although a few studies suggest that chemical carcinogens in tobacco and alcohol appear to enhance HPV trans- forming activity.

The sheer presence of HPV DNA is not suggestive of disease activity and malignant potential as HPV can exist as transient flora in the oral cavity. The integration of HPV into the host genome generally results in the overexpression of E6 and E7oncoproteins. HPV E6 oncoproteins induces p53 destabilization with subsequent loss of apoptosis. E7 activation results in overexpression of $\mathrm{p} 16^{\mathrm{INK} 4 \mathrm{a}}$ supressing the inhibitory activity of $\mathrm{pRb} / \mathrm{E} 2 \mathrm{~F}$ complex which further results in uncontrolled multiplication of epithelial cells ${ }^{30,31}$.

In the present study, although, a significant difference in the incidence of HPV was noted between subjects with OL and controls, it cannot be concluded that HPV has a role in the etiopathogenesis of OL. Further evaluation of the expression of E6 and E7 oncoproteins would provide confirmatory evidence on the role of HPV in leukoplakia.The role of EBV in the etiology of leukoplakia seems limited. Further, studies would give better insight on association of EBV with leukoplakia.

OL has a considerable risk of malignant transformation potential which can result in significant morbidity and mortality. The identification of lesions with a high risk of malignant transformation would be beneficial. Detection of HPV may help identify lesions with high risk of malignant transformation. Such lesions may require complete eradication with regular follow up.

\section{Acknowledgement:-}

The financial assistance given for the conduct of the research from Rajiv Gandhi University of Health Sciences, Karnataka, Bangalore is acknowledged.

\section{References:-}

1. Feller L, Lemmer J (2012): Oral leukoplakia as it relates to HPV infection: A review. Int J Dent;doi 10.1155/2012/540561:1-7

2. Belobrov S, Cornall AM, Young RJ, Koo K, Angel C, Wiesenfeld D, Rischin D, Garland SM, McCullough M 
(2018): The role of human papillomavirus in p16-positive oral cancers. J Oral Pathol Med;47(1):18-24.

3. Kreimer AR, Clifford GM, Boyle P, Franceschi S (2005): Human papillomavirus types in head and neck squamous cell carcinomas worldwide: a systematic review. Cancer Epidemiol Biomarkers Prev;14(2):467-75.

4. Acharya S, Ekalaksananan T, Vatanasapt P, Loyha K, Phusingha P, Promthet S, Kongyingyoes B, Pientong C(2015): Association of Epstein-Barr virus infection with oral squamous cell carcinoma in a case-control study. J Oral Pathol Med;44(4):252-7.

5. She Y, Nong X, Zhang M, Wang M (2017): Epstein-Barr virus infection and oral squamous cell carcinoma risk: a meta-analysis. PloS one;12(10):e0186860.doi: 10.1371/journal.pone.0186860. eCollection 2017

6. Liu W, Shi LJ, Wu L, Feng JQ, Yang X, Li J, Zhou ZT, Zhang CP(2012):Oral cancerdevelopment in patients with leukoplakia-clinicopathologicalfactorsaffectingoutcome. $\quad$ PLoS $\quad$ One.; $\quad 7(4): e 34773$. doi:10.1371/journal.pone.0034773. Epub 2012 Apr 13.

7. Gupta PC, Mehta FS, Daftary DK, et al (1980): Incidence ratesof oral cancer and natural history of oral precancerous lesions in a 10-year follow-up study of Indian villagers. Community Dent Oral Epidemiol; 8: 287-333.

8. Ba'no' czy J, Suga'r L (1972): Longitudinal studies in oral leukoplakias. J Oral Pathol; 1: 265-72.

9. Petti S(2003): Pooled estimate of world leukoplakia prevalence: a systematic review. Oral Oncol; 39: 770-80.

10. Fan JH, Wang JB, Qu CX, Zhang YQ, Taylor PR, Abnet CC, Dawsey SM, Qiao YL (2014):Association between oralleukoplakia and uppergastrointestinalcancers: a 28-yearfollow-upstudy in the LinxianGeneralPopulationTrial. Oral Oncol.; 50(10):971-75.

11.Lee JJ, Hung HC, Cheng SJ, Chen YJ, Chiang CP, Liu BY(2006):Carcinoma and dysplasia in oralleukoplakias in Taiwan: prevalence and riskfactors. Oral Surg Oral Med Oral Pathol Oral Radiol Endod. ;101(4):472-80.

12. Reichart PA(2000): Oral mucosal lesions in a representative cross-sectional study of aging Germans. Community Dent Oral Epidemiol.; 28: 390-98.

13. Waldron CA, Shafer WG(1975): Leukoplakia revisited. A clinicopathologic study of 3256 oral leukoplakias. Cancer; 36: 1386-92.

14. Mehta FS, Pindborg JJ, Gupta PC, Daftary DK(1969): Epidemiologic and histologic study of oral cancer and leukoplakia among 50,915 villagers in India. Cancer; 24: 832-49.

15. Maia HC, Pinto NA, Pereira Jdos S, de Medeiros AM, da Silveira ÉJ, Miguel MC(2016): Potentiallymalignantorallesions: clinicopathologicalcorrelations. Einstein (Sao Paulo).;14(1):35-40.

16. Ba'no' czy J, Suga'r L(1972): Longitudinal studies in oral leukoplakias. J Oral Pathol; 1: 265-72.

17.Ikeda N, Ishii T, Iida S, Kawai T(1991): Epidemiological study of oral leukoplakia based on mass screening for oral mucosal diseases in a selected Japanese population. Community Dent Oral Epidemiol;19:160-63

18. Lind PO(1987): Malignant transformation in oral leukoplakia. Scand J Dent Res; 95: 449-55.

19. Lee JJ, Hung HC, Cheng SJ, Chen YJ, Chiang CP, Liu BY(2006): Carcinoma and dysplasia in oralleukoplakias in Taiwan: prevalence and riskfactors. Oral Surg Oral Med Oral Pathol Oral Radiol Endod.; 101(4):472-80.

20. Bouquot JE, Gorlin RJ(1986):Leukoplakia, lichen planus, and other oral keratoses in 23,616 white Americans over the age of 35 years. Oral Surg Oral Med Oral Pathol; 61: 373-81.

21. Gupta S, Gupta S(2015): Role of human papillomavirus in oral squamous cell carcinoma and oral potentially malignant disorders: A review of the literature. Indian J Dent;6(2):91

22. Saghravanian N, Ghazvini K, Babakoohi S, Firooz A, Mohtasham N(2011):Low prevalence of high risk genotypes of human papilloma virus in normal oral mucosa, oral leukoplakia and verrucous carcinoma. Acta Odontol Scand;69(6):406-9.

23. Llamas-Martinez S, Esparza-Gomez G, Campo-Trapero J, Cancela-Rodriguez P, Bascones-Martinez A, MorenoLópez la, García-núñez J, Cerero-Lapiedra R(2008):Genotypic determination by PCR-RFLP of human papillomavirus in normal oral mucosa, oral leukoplakia and oral squamous cell carcinoma samples in Madrid (Spain). Anticancer Res;28(6A):3733-41

24. Bhosale PG, Pandey M, Desai RS, Patil A, Kane S, Prabhash K, Mahimkar MB(2016): Low prevalence of transcriptionally active human papilloma virus in Indian patients with HNSCC and leukoplakia. Oral Surg Oral Med Oral Pathol Oral Radiol;122(5):609-18.

25. Mathew A, Mody RN, Patait M, Razooki A, Varghese N, Saraf K(2011): Prevalence and relationship of human papilloma virus type 16 and type 18 with oral squamous cell carcinoma and oral leukoplakia in fresh scrappings: a PCR study. Indian J Med Sci;65(5).

26. Khanna R, Rao GR, Tiwary SK, et al(2009): Detection of human papilloma virus 16 and 18 DNA sequences by southern blot hybridization in oral leukoplakia and squamous cell carcinoma. Indian J Surg; 71: 69-72.

27.Prakash P, Khandare M, Kumar M, et al(2013): Immunohistochemical Detection of p16(INK4a) in Leukoplakia and Oral Squamous Cell Carcinoma. J Clin Diagn Res; 7: 2793-2795.

28. Kis A, Fehér E, Gáll T, Tar I, Boda R, Tóth ED, Méhes G, Gergely L, Szarka K(2009): Epstein-Barr virus 
prevalence in oral squamous cell cancer and in potentially malignant oral disorders in an eastern Hungarian population. Eur J Oral Sci;117(5):536-40.

29. D'costa J, Saranath D, Sanghvi V, Mehta AR(1998):Epstein-Barr virus in tobacco-induced oral cancers and oral lesions in patients from India. J Oral Pathol Med;27(2):78-82.

30. Chen X, Zhao Y(2017):Human papillomavirus infection in oral potentially malignant disorders and cancer. Arch Oral Biol;83:334-9

31.Taberna M, Mena M, Pavón MA, Alemany L, Gillison ML, Mesía R(2017): Human papillomavirus-related oropharyngeal cancer. Ann Oncol;28(10):2386-98. 